\title{
新型噻唑并[3,2-a]嘧啶衍生物的合成及其抗肿瘤活性
}

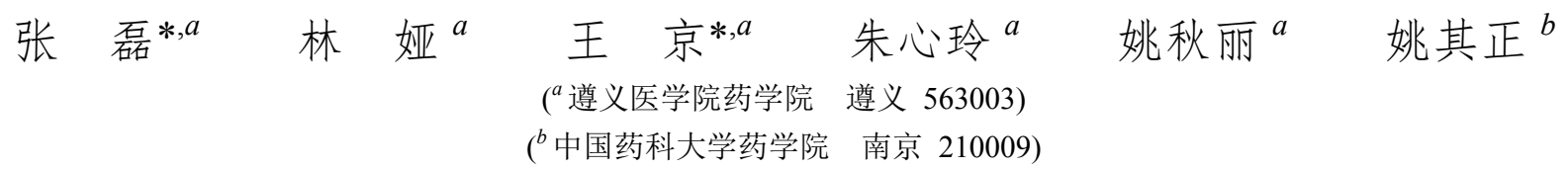

\begin{abstract}
摘要 以取代苯肼盐酸盐为原料, 通过 Vilsmeier-Haack, Biginelli 和 Knoevenagel 等多步反应合成了 9 个含有吡唑取代 基的噻唑并 $[3,2-a]$ 嘧啶衍生物, 并利用 IR, ${ }^{1} \mathrm{H} \mathrm{NMR},{ }^{13} \mathrm{C}$ NMR, ESI-MS 和 HRMS 对目标化合物进行了结构表征. 用四甲 基偶氮唑盐(MTT)法测试了目标产物对人前列腺癌 PC-3 细胞和人肝癌 HepG2 细胞的体外抗增殖活性, 部分化合物表现 出了较好的生物活性, 其中化合物 $\mathbf{5 b}, \mathbf{5 c}, \mathbf{5}$ 和 $5 \mathbf{i}$ 对 PC-3 细胞的抗肿瘤活性优于阳性对照药 5-氟尿嘧啶, $\mathrm{IC}_{50}$ 值分别 为 $29.98,27.69,26.36$ 和 $12.56 \mu \mathrm{mol} / \mathrm{L}$. 进一步的研究表明, 化合物 $\mathbf{5 i}$ 能够诱导 PC-3 细胞调亡, 并使其周期阻滞在 G2/M 期.
\end{abstract}

关键词＼cjkstart噻唑并 $[3,2-a]$ 嘧啶; 抗肿瘤活性; 细胞调亡; 细胞周期

\section{Synthesis and Antiproliferative Activity of Novel Thiazolo[3,2-a]pyrimidine Derivates}

\author{
Zhang, Lei*,a \\ Lin, Ya ${ }^{a} \quad$ Wang, Jing ${ }^{*, a}$ \\ Zhu, Xinling ${ }^{a}$ \\ Yao, Qiuli $^{a}$ \\ Yao, Qizheng ${ }^{b}$ \\ ( ${ }^{a}$ School of Pharmacy, Zunyi Medical College, Zunyi 563003) \\ ( ${ }^{b}$ School of Pharmacy, China Pharmaceutical University, Nanjing 210009)
}

\begin{abstract}
Nine novel thiazolo[3,2-a]pyrimidine derivatives with pyrazole substituent were synthesized from substituted phenylhydrazines via Vilsmeier-Haack, Biginelli and Knoevenagel reactions and characterized by IR, ${ }^{1} \mathrm{H}$ NMR, ${ }^{13} \mathrm{C}$ NMR, ESI-MS and HRMS. The antiproliferative activities of target compounds against human prostate cancer PC-3 and human hepatoma HepG2 cell lines were evaluated by methyl thiazolyl tetrazolium (MTT) assay. The results displayed that several compounds showed moderate to potent antitumor activity. Particularly, compounds $\mathbf{5 b}, \mathbf{5 c}, \mathbf{5 g}$ and $\mathbf{5 i}$ exhibited slightly stronger antitumor activity than positive control 5-fluorouracil (5-FU) against PC-3 cells with $\mathrm{IC}_{50}$ values of 29.98, 27.69, 26.36 and $12.56 \mu \mathrm{mol} / \mathrm{L}$. Moreover, the cellular mechanisms showed that compound $\mathbf{5 i}$ could induce apoptosis and G2/M cell cycle arrest of PC-3 cells.
\end{abstract}

Keywords thiazolo[3,2- $a]$ pyrimidine; anticancer activity; cell apoptosis; cell cycle

二氢嘧啶酮是一类重要的 Biginelli 反应产物, 因其 具有多种药理活性, 所以在药物发现与设计领域中, 二 氢嘧啶酮也被认为是一种优势骨架 ${ }^{[1]}$. 近年来, 二氢嘧 啶酮受到了人们广泛的关注和研究, 越来越多的二氢嘧 啶酮衍生物被合成出来 ${ }^{[2]}$, 并进行了生物活性的篮选, 发现了许多具有研究价值的先导化合物, 为进一步的药 物笁选提供了前期物质基础. 在二氢嘧啶酮衍生物中,
噻唑并 $[3,2-a]$ 嘧啶是一类具有多种重要生物活性的氮、 硫杂环化合物, 如抗氧化 ${ }^{[3]}$ 、抗惊厥 ${ }^{[4]}$ 、抗肿瘤 ${ }^{[5]}$ 、抗病

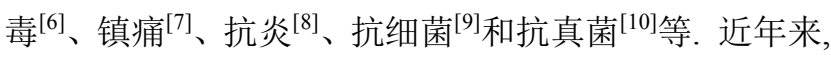
人们发现一些噻唑并 $[3,2-a]$ 嘧啶类化合物能够抑制 $5 a$ 还原酶 ${ }^{[11]} 、 5$-羟色胺-2 受体 ${ }^{[12]}$ 和 2- $C$-甲基- $D$-赤藓醇-2,4环焦磷酸合成酶 $(\mathrm{IspF})^{[13]}$. 此外, 研究还表明, 噻唑并 $[3,2-a]$ 嘧啶衍生物能够有效抑制 Bcl-2 家族抗调亡蛋白

* E-mail: lzhang@zmc.edu.cn; wangjing@zmc.edu.cn

Received August 31, 2014; revised November 9, 2014; published online November 18, 2014.

Project supported by the National Natural Science Fundation of China (No. 21462056), the Priming Scientific Research Foundation for Doctoral Program of Zunyi Medical College (No. F-631), the Department of Science and Technology of Guizhou Province (Nos. [2014]7565, [2014]7557, [2014]4002) and the Education Department of Guizhou Province (No. QJHRCTDZ-2012-03).

国家自然科学基金(No. 21462056)、遵义医学院博士科研启动基金(No. F-631)、贵州省科技厅(Nos. 黔科合 LH 字[2014]7565 号, 黔科合 LH 字 [2014]7557 号, 黔科合人才团队[2014]4002 号)和贵州省教育厅(No. 黔科合人才团队字[2012]03 号)资助项目. 
(如 $\mathrm{Bcl}-2, \mathrm{Bcl}-\mathrm{x}_{\mathrm{L}}$ 和 $\left.\mathrm{Mcl}-1\right)^{[14 \sim 16]}$ 或蛋白磷酸酶

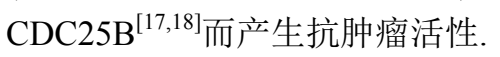

如图 1 所示, 王任小等 ${ }^{[14]}$ 通过苂光偏振结合试验发 现化合物 $\mathbf{a}$ 对 Bcl-2 家族抗调亡蛋白具有较强的抑制活 性, 对 Bcl- $\mathrm{x}_{\mathrm{L}}, \mathrm{Bcl}-2$ 和 $\mathrm{Mcl}-1$ 三种蛋白的抑制常数 $K_{\mathrm{i}}$ 值 分别为 $1.64,2.67$ 和 $1.05 \mu \mathrm{mol} / \mathrm{L}$; 柳红等 ${ }^{[16]}$ 也发现化合 物 b 对 Bcl- $\mathrm{x}_{\mathrm{L}}, \mathrm{Bcl}-2$ 和 $\mathrm{Mcl}$-蛋白具有较好的抑制活性, $\mathrm{IC}_{50}$ 值分别为 $3.4,3.1$ 和 $6.4 \mu \mathrm{mol} / \mathrm{L}$, 此外化合物 $\mathbf{b}$ 能够 抑制多种人肿瘤细胞株的增殖, 其中对人卵巢癌细胞 OVCAR-3 的细胞毒活性最强 $\left(\mathrm{IC}_{50}\right.$ 值为 $\left.1.54 \mu \mathrm{mol} / \mathrm{L}\right)$; 此 外, Kolb 等 ${ }^{[17]}$ 还发现噻唑并 $[3,2-a]$ 嘧啶类化合物能够显 著抑制蛋白磷酸酶 CDC25B 的活性, 其中化合物 $\mathbf{c}$ 的活 性最强 $\left(\mathrm{IC}_{50}\right.$ 值为 $\left.4.5 \mu \mathrm{mol} / \mathrm{L}\right)$, 同时化合物 $\mathbf{c}$ 也能显著抑 制人前列腺癌细胞 $\mathrm{LNCaP}$ 的生长 $\left(\mathrm{IC}_{50}\right.$ 值为 $\left.3.4 \mu \mathrm{mol} / \mathrm{L}\right)$.
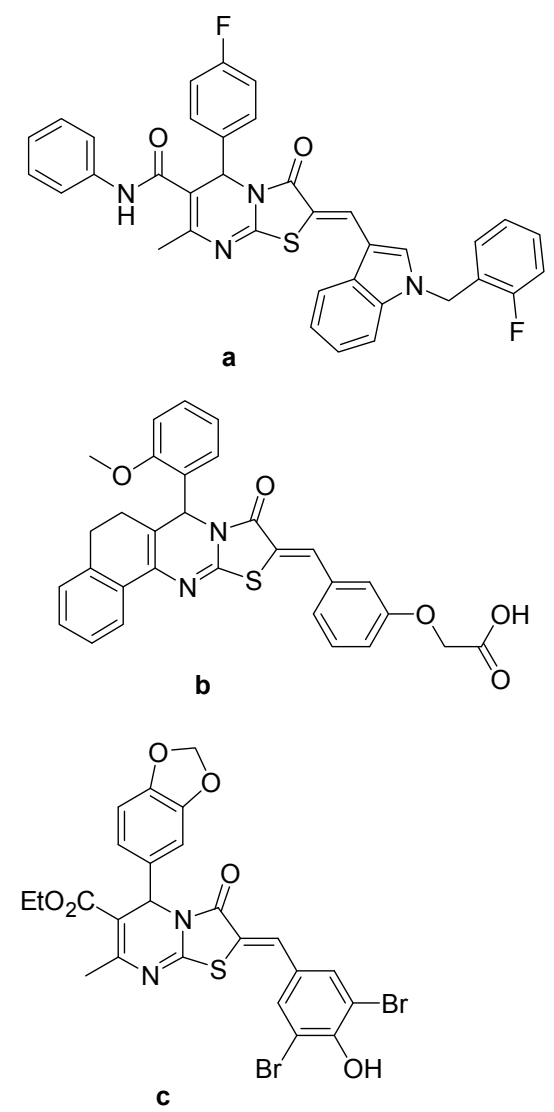

图 1 已报道的噻唑并 $[3,2-a]$ 嘧啶类化合物

Figure 1 Reported thiazolo[3,2-a]pyrimidine derivatives

吡坐也是一种具有众多生物活性的药效团, 近年来

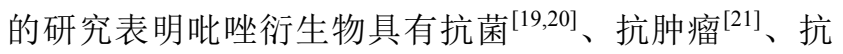

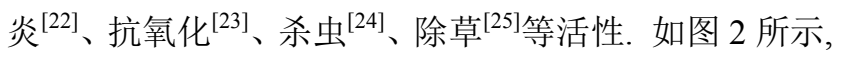
Arai 等 ${ }^{[26]}$ 发现吡唑衍生物 $\mathbf{d}$ 能够强烈抑制抗癌新靶点活 性氧簇 $\mathrm{p} 38 \mathrm{a}$ MAP 激酶的活性, $\mathrm{IC}_{50}$ 值为 $3 \mathrm{nmol} / \mathrm{L}$; 同时, 朱海亮等 ${ }^{[27]}$ 报道了吡唑衍生物 $\mathrm{e}$ 是细胞周期激酶 Aurora-A 的抑制剂( $\mathrm{IC}_{50}$ 值为 $\left.0.16 \mu \mathrm{mol} / \mathrm{L}\right)$, 其对人结肠
癌细胞 HCT116 和人乳腺癌细胞 MCF-7 显示出较强的 细胞毒活性, $\mathrm{IC}_{50}$ 值分别为 0.39 和 $0.46 \mu \mathrm{mol} / \mathrm{L}$.<smiles>Cc1ccc(-n2nc(C(C)(C)C)cc2NC(=O)NCc2cc(F)cc(F)c2Oc2ccnc(N3CCOCC3)n2)cc1</smiles><smiles>CCOc1ccc(NC(=O)c2cn(-c3ccccc3)nc2-c2ccc([N+](=O)[O-])cc2)cc1</smiles>

图 2 已报道的吡唑类化合物

Figure 2 Reported pyrazole derivatives

基于噻唑并 $[3,2-a$ 嘧啶骨架和吡唑药效团均表现出 一定的抗肿瘤活性, 为了得到活性更好的抗肿瘤先导化 合物，根据基于片段的药物发现(FBDD)方法，我们将 噻唑并 $[3,2-a$ ]嘧啶骨架和吡唑药效团进行拼合, 合成了 含有吡唑基团的噻唑并 $[3,2-a]$ 嘧啶类衍生物, 并采用 MTT 法测试目标化合物对人前列腺癌细胞 PC-3 和人肝 癌细胞 HepG-2 的细胞毒性. 合成路线见 Scheme 1.

\section{1 结果与讨论}

\section{1 目标化合物的合成}

以取代苯肼盐酸盐 1 为起始原料, 在醋酸/醋酸钠碱 性体系中游离出取代苯肼, 再与乙酰乙酸乙酯环化得到 中间体吡唑啉酮 2; 2 与 Vilsmeier-Haack 试剂反应生成 中间体吡唑甲醛 $3 ; \mathbf{3}$ 在氨基磺酸的催化下与乙酰乙酸乙 酯、硫脲发生 Biginelli 反应得到中间体二氢嘧啶-2(1H)硫酮 4, 最后通过 “一锅煮” 的方法, 先与氯乙酸环化 得到噻唑并嘧啶中间体，随后与甲酰基苯氧基乙酸发生 Knoevenagel 反应，一步制得目标化合物 5, 方法简单、 高效; 目标化合物结构均经 IR, ${ }^{1} \mathrm{H} \mathrm{NMR},{ }^{13} \mathrm{C} \mathrm{NMR}$, ESI-MS 和 HRMS 确证.

\section{2 体外抗肿瘤活性}

以 5-氟尿嘧啶(5-FU)为阳性药, 用 MTT 法评价了 噻唑并 [3,2-a]嘧啶衍生物 5a 5i 对 PC-3 和 HepG2 细胞 株的体外抗肿瘤活性. 化合物的半数抑制浓度 $\left(\mathrm{IC}_{50}\right)$ 见 

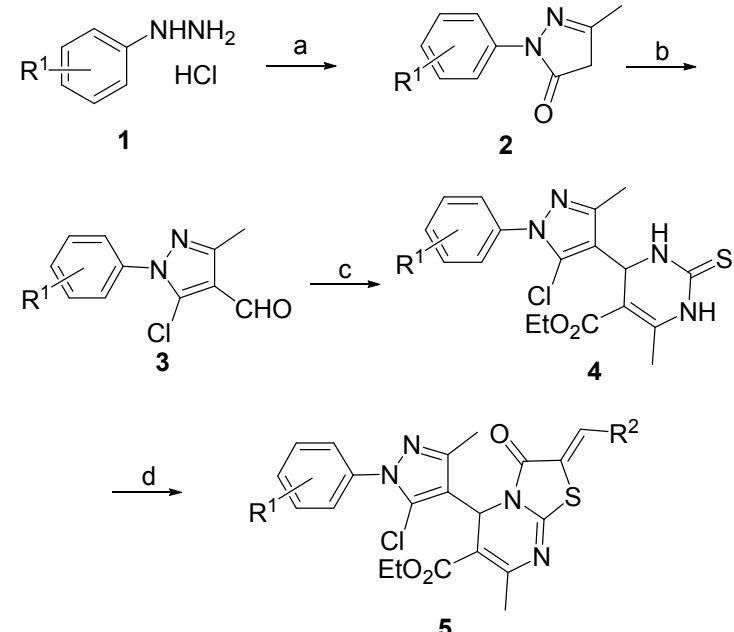

5

\begin{tabular}{|c|c|c|}
\hline Compd. & $\mathrm{R}^{1}$ & $\mathrm{R}^{2}$ \\
\hline $5 \mathbf{a}$ & $4-F$ & \\
\hline $5 b$ & $3-\mathrm{Cl}$ & \\
\hline $5 c$ & $4-\mathrm{OCH}_{3}$ & \\
\hline $5 d$ & $4-F$ & \\
\hline $5 e$ & $3-\mathrm{Cl}$ & \\
\hline $5 f$ & $4-\mathrm{OCH}_{3}$ & \\
\hline $5 \mathrm{~g}$ & $4-F$ & \\
\hline $5 h$ & $3-\mathrm{Cl}$ & \\
\hline $5 \mathbf{i}$ & $4-\mathrm{OCH}_{3}$ & \\
\hline
\end{tabular}

Reagents and conditions: (a) Ethyl acetylacetate, $\mathrm{NaOAc}, \mathrm{AcOH}$, reflux, $12 \mathrm{~h}$. (b) $\mathrm{POCl}_{3}$, dry DMF, $0{ }^{\circ} \mathrm{C}, 0.5 \mathrm{~h}$ then $90 \sim 95{ }^{\circ} \mathrm{C}, 1 \mathrm{~h}$. (c) Thiourea, ethyl acetylacetate, $\mathrm{NH}_{2} \mathrm{SO}_{3} \mathrm{H}$, EtOH, reflux, $10 \mathrm{~h}$. (d) Chloroacetic acid, $\mathrm{R}_{2} \mathrm{CHO}, \mathrm{AcOH}, \mathrm{Ac}_{2} \mathrm{O}, \mathrm{NaOAc}$, reflux, $6 \mathrm{~h}$.

图式 1 目标产物的合成

Scheme 1 The synthesis of target compounds

表 1. 目标化合物表现出对 PC-3 细胞较好的抗增殖活 性, 对 PC-3 细胞的活性显著强于 HepG2 细胞. 其中化 合物 5b, 5c, 5g 和 5i 对 PC-3 细胞株的抗肿瘤活性优于 $5-\mathrm{FU}\left(\mathrm{IC}_{50}=36.36 \mu \mathrm{mol} / \mathrm{L}\right), \mathrm{IC}_{50}$ 值分别为 $29.98,27.69$, 26.36 和 $12.56 \mu \mathrm{mol} / \mathrm{L}$; 化合物 $\mathbf{5 e}$ 和 $\mathbf{5 f}$ 对 PC-3 细胞株 的抑制活性接近 $5-\mathrm{FU}, \mathrm{IC}_{50}$ 值分别为 40.36 和 46.84 $\mu \mathrm{mol} / \mathrm{L}$. 在所有目标化合物中, 只有化合物 $\mathbf{5 i}$ 对 HepG2 细胞株显示出了温和的抗肿瘤活性, $\mathrm{IC}_{50}$ 值为 49.99 $\mu \mathrm{mol} / \mathrm{L}$, 较 $5-\mathrm{Fu}$ 弱 $\left(\mathrm{IC}_{50}=28.38 \mu \mathrm{mol} / \mathrm{L}\right)$.

从体外抗肿瘤活性测试结果初步推断, 当 $\mathrm{R}^{1}$ 取代 基为 3-Cl 或 4- $\mathrm{OCH}_{3}$ 时, 化合物对 PC-3 细胞的抑制活性 显著强于 4-F 基团, 如化合物 $\mathbf{5 b}, \mathbf{5 c}, \mathbf{5 e}$ 和 $\mathbf{5 i}$; 当化合物 分子结构中的氧代乙酸片段处于苯环邻位或对位时, 化
表 1 化合物 $\mathbf{5 a} \sim 5 \mathbf{i}$ 的体外细胞毒活性

Table 1 Cytotoxic activities of $\mathbf{5 a} \sim 5 \mathbf{5}$ in vitro

\begin{tabular}{ccc}
\hline \multirow{2}{*}{ Compd. } & \multicolumn{2}{c}{$\mathrm{IC}_{50}{ }^{a} /\left(\mu \mathrm{mol} \cdot \mathrm{L}^{-1}\right)$} \\
\cline { 2 - 3 } & $\mathrm{PC}-3$ & HepG2 \\
\hline $\mathbf{5 a}$ & $>50$ & $>50$ \\
$\mathbf{5 b}$ & 29.98 & $>50$ \\
$\mathbf{5 c}$ & 27.69 & $>50$ \\
$\mathbf{5 d}$ & $>50$ & $>50$ \\
$\mathbf{5 e}$ & 40.36 & $>50$ \\
$\mathbf{5 f}$ & 46.84 & $>50$ \\
$\mathbf{5 g}$ & 26.36 & $>50$ \\
$\mathbf{5 h}$ & $>50$ & $>50$ \\
$\mathbf{5 i}$ & 12.56 & 49.99 \\
$5-\mathrm{FU}$ & 36.36 & 28.38 \\
\hline$a$ 实验数据为 3 次平行实验平均值 &
\end{tabular}

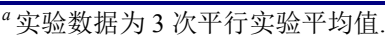

合物的对 PC-3 的活性较强; 但如果氧代乙酸片段处于 苯环对位且邻位有乙氧基取代时，化合物的活性显著降 低, 如化合物 5e 和 $\mathbf{5 f}$.

\section{3 化合物 5i 对 PC-3 细胞凋亡的影响}

PC-3 细胞经 $5 \mathbf{i}(2.5,5$ 和 $10 \mu \mathrm{mol} / \mathrm{L})$ 作用 $72 \mathrm{~h}$ 后, 用 Annexin-V FITC/PI 双染法检测, 结果显示 PC-3 细胞调 亡率分别为 $16.55 \%, 32.14 \%$ 和 $49.28 \%$, 而对照组细胞的 调亡率为 $8.46 \%$, 见图 3. 上述结果表明, 化合物 $\mathbf{5 i}$ 能够 有效的诱导 PC-3 细胞调亡.

\section{4 化合物 5i 对 PC-3 细胞周期的影响}

PC-3 细胞经 $5 \mathbf{i}(2.5,5$ 和 $10 \mu \mathrm{mol} / \mathrm{L})$ 作用 $72 \mathrm{~h}$ 后, 用 PI 单染法检测, 结果显示细胞周期分布发生显著变化. 与对照组相比, $\mathrm{G} 1$ 期细胞显著减少, G2/M 期细胞显著 增加, $\mathrm{S}$ 期细胞无明显差异, 以上结果显示 $\mathbf{5 i}$ 能够诱导 PC-3 细胞引发 G2/M 期阻滞, 见图 4.

\section{2 结论}

本文以取代苯肼盐酸盐为原料, 通过多步 “一锅 煮” 反应, 快速、高效地合成了 9 个新型的含有吡唑的 噻唑并 [3,2- $a$ ] 嘧啶类衍生物. 体外抗肿瘤活性结果显示, 目标产物对 PC-3 细胞具有较强的抗增殖活性, 部分化 合物的抑制活性优于阳性对照药 5-氟尿嘧啶, 其中化合 物 $5 \mathbf{i}$ 的活性最强, $\mathrm{IC}_{50}$ 值为 $12.56 \mu \mathrm{mol} / \mathrm{L}$. 进一步的研究 结果表明其还能够有效的诱导 PC-3 细胞调亡, 并阻滞 PC-3 细胞停滞在 G2/M 期. 目前进一步的结构优化和构 效关系的深入研究正在进行.

\section{3 实验部分}

\section{1 仪器与试剂}

熔点用 Mel-TEMP 熔点仪测定(温度计未经校正); 红外光谱仪为 Nicolet Impact 410 型( $\mathrm{KBr}$ 压片); 质谱仪 为 Agilent $1100 \mathrm{LC} / \mathrm{DAD} / \mathrm{MSD}$ 型(ESI-MS)和 Agilent 

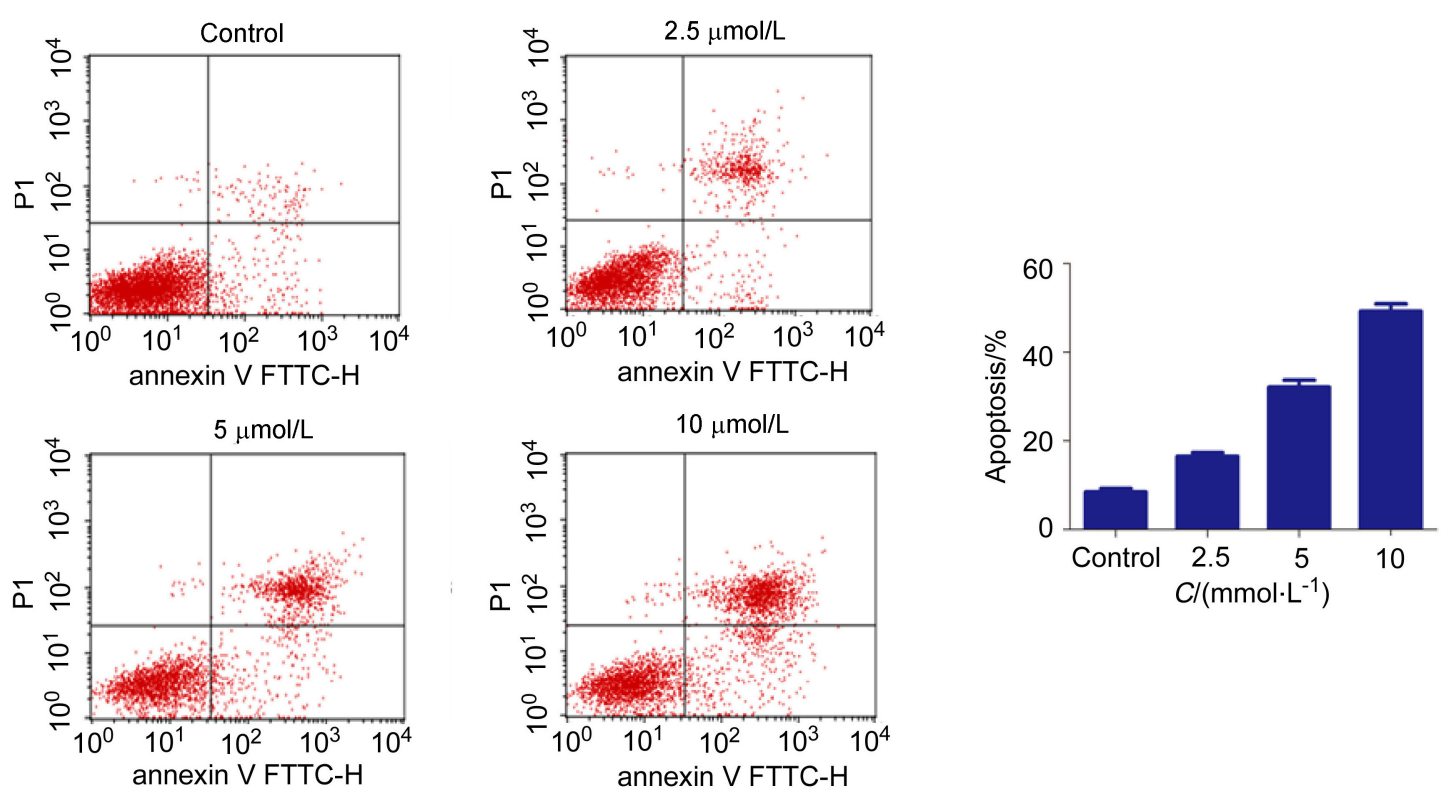

图 3 化合物 5i 对 PC-3 细胞调亡的影响

Figure 3 Effects of compound $\mathbf{5 i}$ on the apoptosis of PC-3 cells
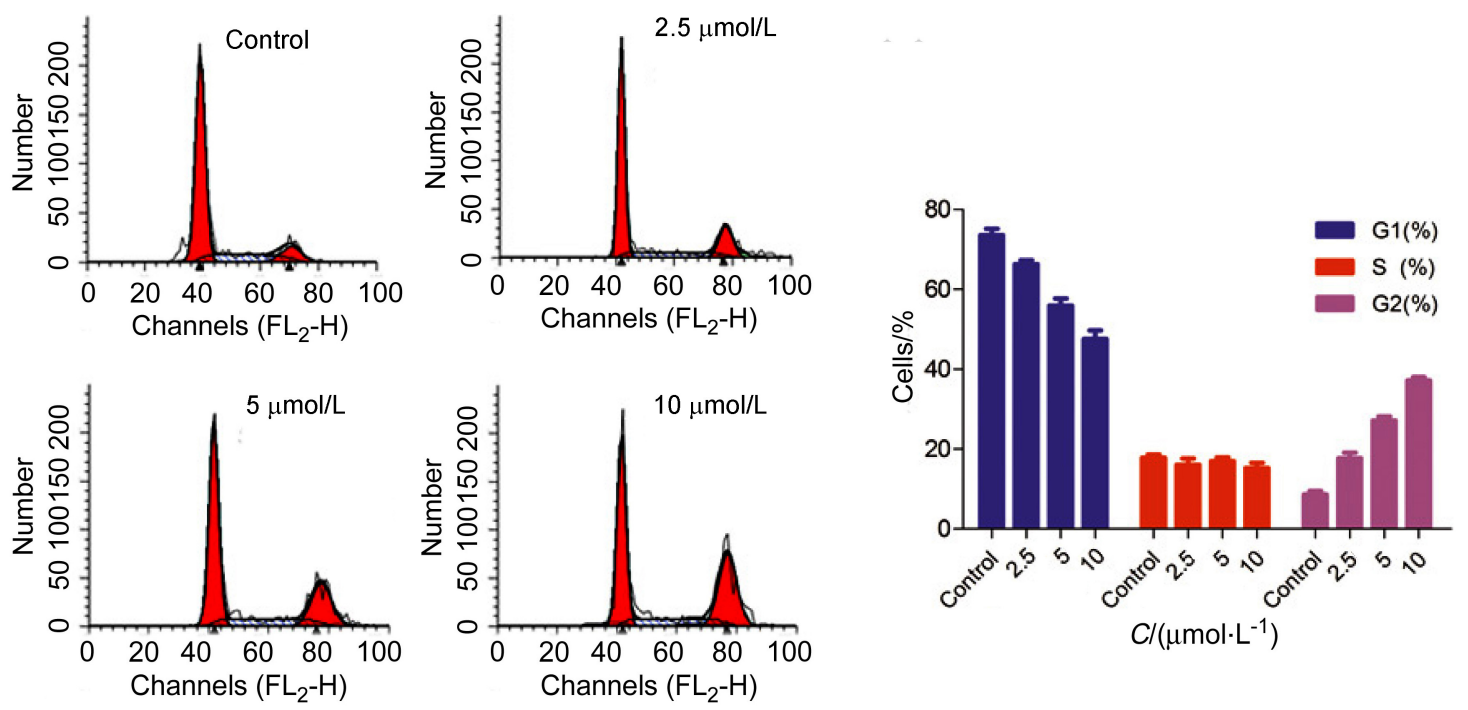

图 4 化合物 5i 对 PC-3 细胞周期的影响

Figure 4 Effects of compound $5 \mathbf{i}$ on the PC-3 cells cycle

Accurate-Mass-Q-TOF-MS 6520 型(HRMS); 核磁共振仪 为 Bruke Avance 300 型和 Agilent-NMR-vnmrs 400 型 $\left(\mathrm{CDCl}_{3}\right.$ 或 DMSO- $d_{6}$ 为溶剂, TMS 为内标). 薄层层析板 和硅胶购自青岛海洋化工厂; 所用试剂均为分析纯, 无 水溶剂用常规方法干燥处理.

\section{2 实验方法}

3.2.13-甲基-1-(取代苯基)-2-吡唑啉-5-酮( $\mathbf{2 a} \sim 2 \mathbf{c}$ )的 合成

将 $0.2 \mathrm{~mol}$ 取代苯肼盐酸盐, $25.24 \mathrm{~mL}(0.2 \mathrm{~mol})$ 乙酰 乙酸乙酯和 $16.4 \mathrm{~g}(0.22 \mathrm{~mol})$ 乙酸钠加入到 $50 \mathrm{~mL}$ 乙酸 中, $\mathrm{N}_{2}$ 保护下回流反应 $12 \mathrm{~h}, \mathrm{TLC}$ 监测反应完全, 冷却至
室温，减压抽滤，滤饼用冰醋酸洗涤 3 次，母液倾入水 中, 搅拌, 抽滤, 滤饼用水洗 3 次, 冰乙醇洗涤 1 次, 粗 品用 $V$ (乙酸乙酯) $: V$ (乙醇 $)=2: 1$ 重结晶 3 次, 得中间 体 $\mathbf{2 a} \sim \mathbf{2 c}$.

3-甲基-1-(4-氟苯基)-2-吡唑啉-5-酮(2a): 白色固体, 产率 70\%. m.p. $151 \sim 152{ }^{\circ} \mathrm{C}$ (文献值 ${ }^{[28]}: 148 \sim 149{ }^{\circ} \mathrm{C}$ ); ${ }^{1} \mathrm{H} \mathrm{NMR}\left(\mathrm{CDCl}_{3}, 300 \mathrm{MHz}\right) \delta: 2.19\left(\mathrm{~s}, 3 \mathrm{H}, \mathrm{CH}_{3}\right), 3.42(\mathrm{~s}$, 2H), 7.17 (t, $J=8.8 \mathrm{~Hz}, 2 \mathrm{H}, \mathrm{ArH}), 7.83(\mathrm{t}, J=6.8 \mathrm{~Hz}, 2 \mathrm{H}$, ArH); ESI-MS $m / z: 193.1[\mathrm{M}+\mathrm{H}]^{+}$.

3-甲基-1-(3-氯苯基)-2-吡唑啉-5-酮(2b)：白色固体, 产率 $65 \%$. m.p. $127{ }^{\circ} \mathrm{C}$ (文献值 ${ }^{[28]}$ : $127 \sim 127.5{ }^{\circ} \mathrm{C}$ ); ${ }^{1} \mathrm{H}$ NMR $\left(\mathrm{CDCl}_{3}, 300 \mathrm{MHz}\right) \delta: 2.20\left(\mathrm{~s}, 3 \mathrm{H}, \mathrm{CH}_{3}\right), 3.43$ (s, 
2H), 7.12 (d, $J=7.9 \mathrm{~Hz}, 1 \mathrm{H}, \mathrm{ArH}), 7.30$ (t, $J=8.2 \mathrm{~Hz}, 1 \mathrm{H}$, $\operatorname{ArH}), 7.81$ (d, $J=8.2 \mathrm{~Hz}, 1 \mathrm{H}, \operatorname{ArH}), 7.93$ (s, $1 \mathrm{H}, \operatorname{ArH})$; ESI-MS $m / z: 209.0[\mathrm{M}+\mathrm{H}]^{+}$.

3-甲基-1-(4-甲氧基苯基)-2-吡唑啉-5-酩(2c): 白色 固体, 产率 $67 \%$. m.p. $127 \sim 128{ }^{\circ} \mathrm{C}$ (文献值 ${ }^{[29]}:$ 124 $\left.126{ }^{\circ} \mathrm{C}\right) ;{ }^{1} \mathrm{H} \mathrm{NMR}\left(\mathrm{CDCl}_{3}, 300 \mathrm{MHz}\right) \delta: 2.17\left(\mathrm{~s}, 3 \mathrm{H}, \mathrm{CH}_{3}\right)$, 3.39 (s, 2H), 3.80 (s, 3H, $\left.\mathrm{OCH}_{3}\right), 6.89$ (d, $J=9.0 \mathrm{~Hz}, 2 \mathrm{H}$, ArH), 7.71 (d, $J=9.0 \mathrm{~Hz}, 2 \mathrm{H}, \mathrm{ArH})$; ESI-MS $m / z: 205.1$ $[\mathrm{M}+\mathrm{H}]^{+}$.

3.2.2 5-氯-3-甲基-1-(取代苯基)吡唑-4-甲醛(3a $\sim 3 \mathbf{c}$ ) 的合成

在 $250 \mathrm{~mL}$ 三口瓶中, 加入 $23 \mathrm{~mL}(0.3 \mathrm{mmol})$ 无水 DMF, 冰盐浴冷却至 $-10{ }^{\circ} \mathrm{C}$ 下, 缓慢滴加 $64 \mathrm{~mL}(0.7$ $\mathrm{mol}$ )三氯氧磷, 滴毕, $0{ }^{\circ} \mathrm{C}$ 下搅拌 $1 \mathrm{~h}$, 向体系中加入 0.1 mol 2a 2c, 缓慢升温至回流, 控温在 $90 \sim 95{ }^{\circ} \mathrm{C}$ 左右, 搅拌反应 $1 \mathrm{~h}$, 冷却至室温, 缓慢倾入 $600 \mathrm{~mL}$ 冰水混合 物中, 搅拌, 过滤, 滤饼水洗至中性, 真空干燥得到中 间体 $\mathbf{3 a} \sim 3 \mathbf{c}$.

5-氯-3-甲基-1-(4-氟苯基)吡唑-4-甲醛(3a) ${ }^{[30]}$ : 浅黄 色固体, 产率 67\%. ${ }^{1} \mathrm{H} \mathrm{NMR}\left(\mathrm{CDCl}_{3}, 300 \mathrm{MHz}\right) \delta: 2.54$ (s, $\left.3 \mathrm{H}, \mathrm{CH}_{3}\right), 7.17 \sim 7.25(\mathrm{~m}, 2 \mathrm{H}, \mathrm{ArH}), 7.49 \sim 7.55(\mathrm{~m}$, 2H, ArH), 9.97 (s, 1H, CHO); ESI-MS m/z: $239.1[\mathrm{M}+$ $\mathrm{H}]^{+}$.

5-氯-3-甲基-1-(3-氯苯基)吡唑-4-甲醛 (3b $)^{[31]}$ : 浅黄 色固体, 产率 $70 \%$. ${ }^{1} \mathrm{H} \mathrm{NMR}\left(\mathrm{CDCl}_{3}, 300 \mathrm{MHz}\right) \delta: 2.54$ (s, $\left.3 \mathrm{H}, \mathrm{CH}_{3}\right), 7.44 \sim 7.51(\mathrm{~m}, 3 \mathrm{H}, \mathrm{ArH}), 7.60(\mathrm{~s}, 1 \mathrm{H}, \mathrm{ArH})$, 9.98 (s, 1H, CHO); ESI-MS m/z: $255.1[\mathrm{M}+\mathrm{H}]^{+}$.

5-氯-3-甲基-1-(4-甲氧基苯基)吡唑-4-甲醛(3c) ${ }^{[32]}$ : 浅黄色固体, 产率 $69 \% .{ }^{1} \mathrm{H} \mathrm{NMR}\left(\mathrm{CDCl}_{3}, 300 \mathrm{MHz}\right) \delta$ : 2.53 (s, $\left.3 \mathrm{H}, \mathrm{CH}_{3}\right), 3.87$ (s, $\left.3 \mathrm{H}, \mathrm{OCH}_{3}\right), 7.00 \sim 7.02$ (d, $J=$ $8.0 \mathrm{~Hz}, 2 \mathrm{H}, \mathrm{ArH}), 7.42 \sim 7.45(\mathrm{~d}, J=8.0 \mathrm{~Hz}, 2 \mathrm{H}, \mathrm{ArH})$, 9.95 (s, 1H, CHO); ESI-MS m/z: $251.1[\mathrm{M}+\mathrm{H}]^{+}$.

3.2.34-[5-氯-3-甲基-1-(取代苯基)-吡唑-4-基]-5-甲 酸乙酯-6-甲基-3,4-二氢嘧啶-2(1H)-硫酮 $(\mathbf{4 a} \sim \mathbf{4} \mathbf{c})$ 的 合成

将 $75.4 \mathrm{mmol} \mathbf{3 a} \sim 3 \mathbf{c}, 11.4 \mathrm{~mL}(90.48 \mathrm{mmol})$ 乙酰乙 酸乙酯, $8.6 \mathrm{~g}(114 \mathrm{mmol})$ 硫艮和 $5.85 \mathrm{~g}(60.32 \mathrm{mmol})$ 氨 基磺酸加入到 $50 \mathrm{~mL}$ 乙醇中, $\mathrm{N}_{2}$ 保护下回流反应 $10 \mathrm{~h}$, TLC 检测反应完全后, 冷却, 抽滤, 滤饼用冰乙醇洗涤 3 次, 烘干, 得到中间体 $\mathbf{4 a} \sim \mathbf{4 c}$.

4-[5-氯-3-甲基-1-(4-氟苯基)-吡唑-4-基]-5-甲酸乙 酯-6-甲基-3,4-二氢嘧啶-2(1H)-硫酮(4a): 白色固体, 产 率 54\% ${ }^{[11]}$. m.p. $235 \sim 236{ }^{\circ} \mathrm{C} ;{ }^{1} \mathrm{H}$ NMR (DMSO- $d_{6}, 300$ MHz) $\delta: 1.09$ (t, $\left.J=7.0 \mathrm{~Hz}, 3 \mathrm{H}, \mathrm{OCH}_{2} \mathrm{CH}_{3}\right), 2.19$ (s, $3 \mathrm{H}$, $\left.\mathrm{CH}_{3}\right), 2.27\left(\mathrm{~s}, 3 \mathrm{H}, \mathrm{CH}_{3}\right), 3.99 \sim 4.09\left(\mathrm{~m}, 2 \mathrm{H}, \mathrm{OCH}_{2} \mathrm{CH}_{3}\right)$, $5.28(\mathrm{~s}, 1 \mathrm{H}, \mathrm{CH}), 7.35 \sim 7.40(\mathrm{~m}, 2 \mathrm{H}, \mathrm{ArH}), 7.51 \sim 7.56$ (m, 2H, ArH), $9.45(\mathrm{~s}, 1 \mathrm{H}, \mathrm{NH}), 10.35(\mathrm{~s}, 1 \mathrm{H}, \mathrm{NH})$; ESI-MS $m / z: 409.2[\mathrm{M}+\mathrm{H}]^{+}$.

4-[5-氯-3-甲基-1-(3-氯苯基)-吡唑-4-基]-5-甲酸乙 酯-6-甲基-3,4-二氢嘧啶-2(1H)-硫酮(4b): 白色固体, 产 率 48\%. m.p. 195 196 ${ }^{\circ} \mathrm{C}$; ${ }^{1} \mathrm{H}$ NMR (DMSO- $d_{6}, 300$ MHz) $\delta: 1.07$ (t, $\left.J=7.0 \mathrm{~Hz}, 3 \mathrm{H}, \mathrm{OCH}_{2} \mathrm{CH}_{3}\right), 2.21(\mathrm{~s}, 3 \mathrm{H}$, $\left.\mathrm{CH}_{3}\right), 2.27$ (s, $\left.3 \mathrm{H}, \mathrm{CH}_{3}\right), 3.97 \sim 4.05\left(\mathrm{~m}, 2 \mathrm{H}, \mathrm{OCH}_{2} \mathrm{CH}_{3}\right.$ ), 5.29 (s, 1H, CH), 7.49 7.60 (m, 4H, , ArH), 9.45 (s, 1H, $\mathrm{NH}), 10.38$ (s, 1H, NH); ESI-MS $m / z$ : $425.1[\mathrm{M}+\mathrm{H}]^{+}$.

4-[5-氯-3-甲基-1-(4-甲氧基苯基)-吡唑-4-基]-5-甲 酸乙酯-6-甲基-3,4-二氢嘧啶-2(1H)-硫酮(4c): 白色固体, 产率 57\%. m.p. $248 \sim 250{ }^{\circ} \mathrm{C} ;{ }^{1} \mathrm{H}$ NMR (DMSO- $d_{6}, 300$ MHz) $\delta: 1.09\left(\mathrm{t}, J=7.0 \mathrm{~Hz}, 3 \mathrm{H}, \mathrm{OCH}_{2} \mathrm{CH}_{3}\right), 2.18(\mathrm{~s}, 3 \mathrm{H}$, $\left.\mathrm{CH}_{3}\right), 2.27$ (s, $\left.3 \mathrm{H}, \mathrm{CH}_{3}\right), 3.81\left(\mathrm{~s}, 3 \mathrm{H}, \mathrm{OCH}_{3}\right), 3.93 \sim 4.09$ (m, $\left.2 \mathrm{H}, \mathrm{OCH}_{2} \mathrm{CH}_{3}\right), 5.27(\mathrm{~s}, 1 \mathrm{H}, \mathrm{CH}), 7.05 \sim 7.08(\mathrm{~d}, J=$ $8.8 \mathrm{~Hz}, 2 \mathrm{H}, \mathrm{ArH}), 7.35 \sim 7.38(\mathrm{~d}, J=8.8 \mathrm{~Hz}, 2 \mathrm{H}, \mathrm{ArH})$, 9.44 (s, 1H, NH), 10.35 (s, 1H, NH); ESI-MS m/z: 421.2 $[\mathrm{M}+\mathrm{H}]^{+}$.

3.2.4 目标化合物 2-[4-((6-) ( 氧羰酯)-5-(5-氯-3-甲 基-1-(取代苯基)-吡唑-4-基)-3-氧代-7-甲基-噻唑并 [3,2- $a$ 嘧啶-2(5H)-亚基)甲基)苯氧基]乙酸 $(\mathbf{5 a} \sim 5 \mathbf{5 i})$ 的 合成

将中间体 $4 \mathbf{a} \sim \mathbf{4 c}(2 \mathrm{mmol})$ 、甲酰基苯氧基乙酸(2 $\mathrm{mmol})$ 、氯乙酸 $(2.2 \mathrm{mmol})$ 和乙酸钠 $(2 \mathrm{mmol})$ 加入到 $7 \mathrm{~mL}$ 乙酸/乙酸酐混合溶剂中 $(V: V=4: 3), \mathrm{N}_{2}$ 保护下回流反 应 $6 \mathrm{~h}, \mathrm{TLC}$ 监测反应完全后, 冷却, 倾入冰水混合物中, 搅拌, 抽滤, 滤饼水洗 3 次, 烘干, 甲醇重结晶, 得到目 标产物 $\mathbf{5 a} \sim \mathbf{5 i}$.

2-[4-((6-(乙氧羰酯)-5-(5-氯-3-甲基-1-(4-氟苯基)吡唑-4-基)-3-氧代-7-甲基-噻唑并 [3,2- $a$ ]嘧啶-2(5H)-亚 基)甲基)苯氧基]乙酸(5a): 黄色固体, 产率 $65 \%$. m.p. 151 $\sim 152{ }^{\circ} \mathrm{C} ;{ }^{1} \mathrm{H}$ NMR (DMSO- $\left.d_{6}, 300 \mathrm{MHz}\right) \delta: 1.15$ (t, $\left.J=6.9 \mathrm{~Hz}, 3 \mathrm{H}, \mathrm{OCH}_{2} \mathrm{CH}_{3}\right), 2.29\left(\mathrm{~s}, 3 \mathrm{H}, \mathrm{CH}_{3}\right), 2.37$ (s, $3 \mathrm{H}$, $\left.\mathrm{CH}_{3}\right), 4.09 \sim 4.13\left(\mathrm{~m}, 2 \mathrm{H}, \mathrm{OCH}_{2} \mathrm{CH}_{3}\right), 4.78(\mathrm{~s}, 2 \mathrm{H}$, $\left.\mathrm{OCH}_{2} \mathrm{CO}\right), 6.08(\mathrm{~s}, 1 \mathrm{H}, \mathrm{CH}), 7.07(\mathrm{~d}, J=8.6 \mathrm{~Hz}, 2 \mathrm{H}$, ArH), $7.35(\mathrm{~d}, J=8.7 \mathrm{~Hz}, 2 \mathrm{H}, \mathrm{ArH}), 7.51 \sim 7.58(\mathrm{~m}, 4 \mathrm{H}$, $\mathrm{ArH}$ ), 7.79 (s, $1 \mathrm{H}, \mathrm{CH}=$ ); ${ }^{13} \mathrm{C}$ NMR (DMSO- $d_{6}, 75 \mathrm{MHz}$ ) $\delta: 12.72,14.51,22.90,46.88,60.64,65.05,105.52,115.96$, $116.41,116.71,117.02,117.51,126.23,126.82,127.62$, $127.74,132.51,133.28,134.24,148.99,152.18,155.93$, $160.17,160.25,163.51,164.90,165.41,170.19$; IR (KBr) v: 3663, 3545, 3138, 2979, 2920, 2330, 2365, 1761, 1702, 1587, 1549, 1504, 1366, 1328, 1307, 1233, 1151, 1065 $\mathrm{cm}^{-1}$; ESI-MS m/z: $609.1[\mathrm{M}-\mathrm{H}]^{-}$; HRMS calcd for 
$\mathrm{C}_{29} \mathrm{H}_{25} \mathrm{ClFN}_{4} \mathrm{O}_{6} \mathrm{~S}[\mathrm{M}+\mathrm{H}]^{+}$611.1162, found 611.1163.

2-[4-((6-(乙氧羰酯)-5-(5-氯-3-甲基-1-(3-氯苯基)吡唑-4-基)-3-氧代-7-甲基-噻唑并 [3,2- $a$ ]嘧啶-2(5H)-亚 基)甲基)苯氧基]乙酸(5b): 黄色固体, 产率 71\%. m.p. $164 \sim 165{ }^{\circ} \mathrm{C}$; ${ }^{1} \mathrm{H}$ NMR (DMSO- $\left.d_{6}, 300 \mathrm{MHz}\right) \delta$ : 1.15 (t, $\left.J=7.1 \mathrm{~Hz}, 3 \mathrm{H}, \mathrm{OCH}_{2} \mathrm{CH}_{3}\right), 2.31\left(\mathrm{~s}, 3 \mathrm{H}, \mathrm{CH}_{3}\right), 2.37$ (s, $3 \mathrm{H}$, $\left.\mathrm{CH}_{3}\right), 4.08 \sim 4.16\left(\mathrm{~m}, 2 \mathrm{H}, \mathrm{OCH}_{2} \mathrm{CH}_{3}\right), 4.91(\mathrm{~s}, 1 \mathrm{H}$, $\left.\mathrm{OCH}_{2} \mathrm{CO}\right), 6.08(\mathrm{~s}, 1 \mathrm{H}, \mathrm{CH}), 7.10(\mathrm{~d}, J=8.7 \mathrm{~Hz}, 2 \mathrm{H}$, $\mathrm{ArH}), 7.49 \sim 7.61(\mathrm{~m}, 6 \mathrm{H}, \mathrm{ArH}), 7.79(\mathrm{~s}, 1 \mathrm{H}, \mathrm{CH}=) ;{ }^{13} \mathrm{C}$ NMR (DMSO- $\left.d_{6}, 75 \mathrm{MHz}\right) \delta: 12.72,14.51,22.91,46.86$, $60.66,65.11,105.45,116.03,117.23,118.06,123.78$, $124.96,126.49,126.86,128.75,131.33,132.50,133.19$, $133.85,139.00,149.57,152.27,155.90,159.93,164.89$, 165.38, 169.23; IR (KBr) v: 3504, 2991, 2914, 2849, 1773, $1708,1595,1556,1511,1376,1265,1324,1303,1263$, 1233, 1215, 1160, $1079 \mathrm{~cm}^{-1}$; ESI-MS $m / z: 625.1[\mathrm{M}-$ $\mathrm{H}]^{-}$; HRMS calcd for $\mathrm{C}_{29} \mathrm{H}_{25} \mathrm{Cl}_{2} \mathrm{~N}_{4} \mathrm{O}_{6} \mathrm{~S}[\mathrm{M}+\mathrm{H}]^{+}$ 627.0866, found 627.0865 .

2-[4-((6-(乙氧羰酯)-5-(5-氯-3-甲基-1-(4-甲氧基苯 基)-吡唑-4-基)-3-氧代-7-甲基-噻唑并 $[3,2-a]$ 嘧啶2(5H)-亚基)甲基)苯氧基]乙酸 $(\mathbf{5 c})$ : 黄色固体, 产率 74\%. m.p. $152 \sim 155{ }^{\circ} \mathrm{C} ;{ }^{1} \mathrm{H}$ NMR (DMSO- $d_{6}, 300 \mathrm{MHz}$ ) $\delta$ : $1.15\left(\mathrm{t}, J=6.9 \mathrm{~Hz}, 3 \mathrm{H}, \mathrm{OCH}_{2} \mathrm{CH}_{3}\right), 2.27\left(\mathrm{~s}, 3 \mathrm{H}, \mathrm{CH}_{3}\right)$, $2.36\left(\mathrm{~s}, 3 \mathrm{H}, \mathrm{CH}_{3}\right), 3.79\left(\mathrm{~s}, 3 \mathrm{H}, \mathrm{OCH}_{3}\right), 4.05 \sim 4.16(\mathrm{~m}, 2 \mathrm{H}$, $\left.\mathrm{OCH}_{2} \mathrm{CH}_{3}\right), 4.78\left(\mathrm{~s}, \quad 1 \mathrm{H}, \quad \mathrm{OCH}_{2} \mathrm{CO}\right), 4.91(\mathrm{~s}, \quad 1 \mathrm{H}$, $\left.\mathrm{OCH}_{2} \mathrm{CO}\right), 6.07$ (s, 1H, CH), 7.02 7.13 (m, 4H, ArH), 7.35 (d, $J=8.8 \mathrm{~Hz}, 2 \mathrm{H}, \mathrm{ArH}), 7.55(\mathrm{~d}, J=8.6 \mathrm{~Hz}, 2 \mathrm{H}$, $\mathrm{ArH}), 7.79$ (s, $1 \mathrm{H}, \mathrm{CH}=$ ); ${ }^{13} \mathrm{C}$ NMR (DMSO- $d_{6}, 75 \mathrm{MHz}$ ) $\delta: 12.71,14.50,22.86,46.95,55.93,60.61,65.08,105.67$, $114.73,115.97,116.98,117.07,126.26,126.51,126.71$, $126.93,130.90,132.50,133.25,148.42,152.02,155.86$, 159.49, 159.92, 160.17, 164.89, 165.43, 170.15; IR (KBr) $v: 3588,3158,2979,2931,2837,2555,2335,1764,1705$, 1590, 1552, 1504, 1363, 1304, 1257, 1236, 1157, 1077, 1054, $998 \mathrm{~cm}^{-1}$; ESI-MS m/z: $621.1[\mathrm{M}-\mathrm{H}]^{-}$; HRMS calcd for $\mathrm{C}_{30} \mathrm{H}_{28} \mathrm{ClN}_{4} \mathrm{O}_{7} \mathrm{~S}[\mathrm{M}+\mathrm{H}]^{+}$623.1362, found 623.1370 .

2-[4-((6-(乙氧羰酯)-5-(5-氯-3-甲基-1-(4-氟苯基)吡唑-4-基)-3-氧代-7-甲基-噻唑并 [3,2- $a$ ] 嘧啶-2(5H)-亚 基)甲基)-3-乙氧基苯氧基]乙酸(5d): 黄色固体, 产率 71\%. m.p. $165 \sim 167{ }^{\circ} \mathrm{C} ;{ }^{1} \mathrm{H}$ NMR (DMSO- $d_{6}, 300 \mathrm{MHz}$ ) $\delta: 1.15\left(\mathrm{t}, J=7.0 \mathrm{~Hz}, 3 \mathrm{H}, \mathrm{OCH}_{2} \mathrm{CH}_{3}\right), 1.36(\mathrm{t}, J=6.9 \mathrm{~Hz}$, $\left.3 \mathrm{H}, \mathrm{OCH}_{2} \mathrm{CH}_{3}\right), 2.29\left(\mathrm{~s}, 3 \mathrm{H}, \mathrm{CH}_{3}\right), 2.36\left(\mathrm{~s}, 3 \mathrm{H}, \mathrm{CH}_{3}\right)$, $4.06 \sim 4.15\left(\mathrm{~m}, 4 \mathrm{H}, 2 \times \mathrm{OCH}_{2} \mathrm{CH}_{3}\right), 4.91(\mathrm{~s}, 2 \mathrm{H}$, $\left.\mathrm{OCH}_{2} \mathrm{CO}\right), 6.08$ (s, 1H, CH), $7.02(\mathrm{t}, J=8.4 \mathrm{~Hz}, 1 \mathrm{H}, \mathrm{ArH})$,
$7.14 \sim 7.21(\mathrm{~m}, 2 \mathrm{H}, \mathrm{ArH}), 7.35(\mathrm{t}, J=8.8 \mathrm{~Hz}, 2 \mathrm{H}, \operatorname{ArH})$, $7.51 \sim 7.56(\mathrm{~m}, 2 \mathrm{H}, \mathrm{ArH}), 7.78(\mathrm{~s}, 1 \mathrm{H}, \mathrm{CH}=) ;{ }^{13} \mathrm{C} \mathrm{NMR}$ (DMSO- $\left.d_{6}, 100 \mathrm{MHz}\right) \delta: 12.73,14.51,15.02,22.89,46.84$, 52.35, 60.64, 64.43, 65.30, 105.48, 114.07, 114.99, 116.45, $116.69,117.38,117.49,123.92,126.80,127.65,127.75$, $133.58,134.25,148.65,148.98,149.75,152.19,155.91$, $160.65,164.81,165.39,169.35$; IR (KBr) $v: 3734,3415$, 3120, 2997, 2938, 2873, 2365, 1755, 1714, 1699, 1555, 1507, 1366, 1304, 1236, 1201, 1163,1142, $1077 \mathrm{~cm}^{-1}$; ESI-MS $m / z$ : $653.1[\mathrm{M}-\mathrm{H}]^{-}$; HRMS calcd for $\mathrm{C}_{31} \mathrm{H}_{29} \mathrm{Cl}-$ $\mathrm{FN}_{4} \mathrm{O}_{7} \mathrm{~S}[\mathrm{M}+\mathrm{H}]^{+}$655.1424, found 655.1427.

2-[4-((6-(乙氧羰酯)-5-(5-氯-3-甲基-1-(3-氯苯基) 吡唑-4-基)-3-氧代-7-甲基-噻唑并 $[3,2-a]$ 嘧啶-2(5H)-亚 基)甲基)-3-乙氧基苯氧基]乙酸 (5e): 黄色固体, 产率 66\%. m.p. $181 \sim 183{ }^{\circ} \mathrm{C} ;{ }^{1} \mathrm{H}$ NMR (DMSO- $d_{6}, 300 \mathrm{MHz}$ ) $\delta: 1.15\left(\mathrm{t}, J=7.0 \mathrm{~Hz}, 3 \mathrm{H}, \mathrm{OCH}_{2} \mathrm{CH}_{3}\right), 1.36$ (t, $J=6.8 \mathrm{~Hz}$, $\left.3 \mathrm{H}, \mathrm{OCH}_{2} \mathrm{CH}_{3}\right), 2.31\left(\mathrm{~s}, 3 \mathrm{H}, \mathrm{CH}_{3}\right), 2.37\left(\mathrm{~s}, 3 \mathrm{H}, \mathrm{CH}_{3}\right)$, $4.06 \sim 4.16\left(\mathrm{~m}, 4 \mathrm{H}, 2 \times \mathrm{OCH}_{2} \mathrm{CH}_{3}\right), 5.14(\mathrm{~s}, 2 \mathrm{H}$, $\left.\mathrm{OCH}_{2} \mathrm{CO}\right), 6.08$ (s, 1H, CH), $7.02(\mathrm{t}, J=8.8 \mathrm{~Hz}, 1 \mathrm{H}, \mathrm{ArH})$, 7.14 (d, $J=8.4 \mathrm{~Hz}, 1 \mathrm{H}, \mathrm{ArH}), 7.20$ (s, 1H, ArH), 7.48 7.57 (m, 3H, ArH), 7.61 (s, 1H, ArH), $7.77(\mathrm{~s}, 1 \mathrm{H}, \mathrm{CH}=)$; ${ }^{13} \mathrm{C}$ NMR (DMSO- $\left.d_{6}, 75 \mathrm{MHz}\right) \delta: 12.69,14.47,15.01$, 22.77, 46.84, 60.67, 64.50, 65.44, 105.37, 114.20, 115.09, $117.25,118.02,123.71,124.02,124.91,126.83,128.71$, $131.29,113.84,138.97,148.67,149.58,149.87,152.09$, $156.02,164.75,165.29,169.28,170.16$; IR (KBr) v: 3557, 3410, 3126, 2991, 2920, 2849, 2330, 2176, 1733, 1712, 1592, 1544, 1369, 1308, 1255, 1234, 1162, 1145, 1067, $992 \mathrm{~cm}^{-1}$; ESI-MS $m / z$ : $669.0[\mathrm{M}-\mathrm{H}]^{-}$; HRMS calcd for $\mathrm{C}_{31} \mathrm{H}_{29} \mathrm{Cl}_{2} \mathrm{~N}_{4} \mathrm{O}_{7} \mathrm{~S}[\mathrm{M}+\mathrm{H}]^{+}$671.1129, found 671.1133.

2-[4-((6-(乙氧羰酯)-5-(5-氯-3-甲基-1-(4-甲氧基苯 基)-吡唑-4-基)-3-氧代-7-甲基-噻唑并 [3,2- $a$ 嘧啶2(5H)-亚基)甲基)-3-乙氧基苯氧基]乙酸(5f): 黄色固体, 产率 62\%. m.p. 191 $193{ }^{\circ} \mathrm{C}$; ${ }^{1} \mathrm{H}$ NMR (DMSO- $d_{6}, 300$ MHz) $\delta: 1.15\left(\mathrm{t}, J=7.0 \mathrm{~Hz}, 3 \mathrm{H}, \mathrm{OCH}_{2} \mathrm{CH}_{3}\right), 1.36(\mathrm{t}, J=$ $\left.6.9 \mathrm{~Hz}, 3 \mathrm{H}, \mathrm{OCH}_{2} \mathrm{CH}_{3}\right), 2.27\left(\mathrm{~s}, 3 \mathrm{H}, \mathrm{CH}_{3}\right), 2.36(\mathrm{~s}, 3 \mathrm{H}$, $\left.\mathrm{CH}_{3}\right), 3.79\left(\mathrm{~s}, 3 \mathrm{H}, \mathrm{OCH}_{3}\right), 4.06 \sim 4.17(\mathrm{~m}, 4 \mathrm{H}, 2 \times$ $\left.\mathrm{OCH}_{2} \mathrm{CH}_{3}\right), 4.91$ (s, $\left.2 \mathrm{H}, \mathrm{OCH}_{2} \mathrm{CO}\right), 6.06(\mathrm{~s}, 1 \mathrm{H}, \mathrm{CH}), 7.02$ (t, $J=8.5 \mathrm{~Hz}, 3 \mathrm{H}, \mathrm{ArH}), 7.13 \sim 7.21(\mathrm{~m}, 2 \mathrm{H}, \mathrm{ArH}), 7.35$ (d, $J=8.9 \mathrm{~Hz}, 2 \mathrm{H}, \mathrm{ArH}), 7.77$ (s, $1 \mathrm{H}, \mathrm{CH}=) ;{ }^{13} \mathrm{C} \mathrm{NMR}$ (DMSO- $\left.d_{6}, 100 \mathrm{MHz}\right) \delta: 12.71,14.48,15.02,22.74,46.89$, $52.35,55.90,60.64,64.42,65.31,105.58,114.05,114.69$, $114.98,116.91,117.25,123.95,126.70,126.77,126.93$, $130.83,133.74,148.41,148.64,149.78,151.83,156.00$, $159.45,164.75,165.35,169.33,170.22$; IR (KBr) v: 3675, 
$3439,3120,2985,2932,2336,2218,1731,1705,1658$, $1584,1560,1515,1393,1301,1357,1163,1124,1062$, $998 \mathrm{~cm}^{-1}$; ESI-MS m/z: $665.1[\mathrm{M}-\mathrm{H}]^{-}$; HRMS calcd for $\mathrm{C}_{32} \mathrm{H}_{32} \mathrm{ClN}_{4} \mathrm{O}_{8} \mathrm{~S}[\mathrm{M}+\mathrm{H}]^{+}$667.1624, found 667.1630.

2-[2-((6-(乙氧羰酯)-5-(5-氯-3-甲基-1-(4-氟苯基)吡唑-4-基)-3-氧代-7-甲基-噻唑并 [3,2- $a$ ] 嘧啶-2 (5H)-亚 基)甲基)苯氧基]乙酸 $(5 \mathrm{~g})$ ：黄色固体, 产率 $63 \%$. m.p. $174 \sim 175{ }^{\circ} \mathrm{C} ;{ }^{1} \mathrm{H}$ NMR (DMSO- $\left.d_{6}, 300 \mathrm{MHz}\right) \delta: 1.15$ (t, $\left.J=7.0 \mathrm{~Hz}, 3 \mathrm{H}, \mathrm{OCH}_{2} \mathrm{CH}_{3}\right), 2.29$ (s, $\left.3 \mathrm{H}, \mathrm{CH}_{3}\right), 2.37$ (s, $3 \mathrm{H}$, $\left.\mathrm{CH}_{3}\right), 4.06 \sim 4.17\left(\mathrm{~m}, 2 \mathrm{H}, \mathrm{OCH}_{2} \mathrm{CH}_{3}\right), 4.98(\mathrm{~s}, 2 \mathrm{H}$, $\left.\mathrm{OCH}_{2} \mathrm{CO}\right), 6.08(\mathrm{~s}, 1 \mathrm{H}, \mathrm{CH}), 7.04 \sim 7.18(\mathrm{~m}, 2 \mathrm{H}, \mathrm{ArH})$, $7.35(\mathrm{t}, J=8.7 \mathrm{~Hz}, 2 \mathrm{H}, \mathrm{ArH}), 7.44 \sim 7.50(\mathrm{~m}, 2 \mathrm{H}, \mathrm{ArH})$, $7.53 \sim 7.58(\mathrm{~m}, 2 \mathrm{H}, \mathrm{ArH}), 8.05$ (s, $1 \mathrm{H}, \mathrm{CH}=) ;{ }^{13} \mathrm{C} \mathrm{NMR}$ (DMSO- $\left.d_{6}, 100 \mathrm{MHz}\right) \delta: 12.73,14.51,22.88,46.89,52.41$, 60.66, 65.34, 105.66, 113.44, 116.44, 116.67, 117.35, $120.37,122.15,122.31,126.84,127.68,129.20,132.97$, 134.26, 148.98, 152.04, 155.88, 156.86, 160.65, 164.86, 165.38, 169.27, 170.14; IR (KBr) v: 3545, 3410, 3120, 2926, 2849, 1764, 1705, 1625, 1593, 1552, 1513, 1372, 1328, 1304, 1233, 1157, 1133, $1077 \mathrm{~cm}^{-1}$; ESI-MS $\mathrm{m} / z$ : $609.4[\mathrm{M}-\mathrm{H}]^{-}$; HRMS calcd for $\mathrm{C}_{29} \mathrm{H}_{25} \mathrm{ClFN}_{4} \mathrm{O}_{6} \mathrm{~S}[\mathrm{M}+$ $\mathrm{H}]^{+}$611.1162, found 611.1159.

2-[2-((6-(乙氧羰酯)-5-(5-氯-3-甲基-1-(3-氯苯基)吡唑-4-基)-3-氧代-7-甲基-噻唑并 [3,2- $a$ 嘧啶-2(5H)-亚 基)甲基)苯氧基]乙酸 $(5 \mathbf{h})$ : 黄色固体, 产率 73\%. m.p. 174 $\sim 175{ }^{\circ} \mathrm{C} ;{ }^{1} \mathrm{H}$ NMR (DMSO- $\left.d_{6}, 300 \mathrm{MHz}\right) \delta: 1.15$ (t, $J=7.0 \mathrm{~Hz}, 3 \mathrm{H}, \mathrm{OCH}_{2} \mathrm{CH}_{3}$ ), $2.32\left(\mathrm{~s}, 3 \mathrm{H}, \mathrm{CH}_{3}\right), 2.37$ (s, $3 \mathrm{H}$, $\left.\mathrm{CH}_{3}\right), 4.06 \sim 4.17\left(\mathrm{~m}, 2 \mathrm{H}, \mathrm{OCH}_{2} \mathrm{CH}_{3}\right), 4.86(\mathrm{~s}, 1 \mathrm{H}$, $\left.\mathrm{OCH}_{2} \mathrm{CO}\right), 4.98\left(\mathrm{~s}, 1 \mathrm{H}, \mathrm{OCH}_{2} \mathrm{CO}\right), 6.08(\mathrm{~s}, 1 \mathrm{H}, \mathrm{CH})$, $7.05 \sim 7.18(\mathrm{~m}, 2 \mathrm{H}, \mathrm{ArH}), 7.44 \sim 7.57$ (m, 5H, ArH), 7.62 (s, $1 \mathrm{H}, \mathrm{ArH}), 8.06(\mathrm{~s}, 1 \mathrm{H}, \mathrm{CH}=) ;{ }^{13} \mathrm{C}$ NMR (DMSO- $d_{6}$, $100 \mathrm{MHz}) \delta: 12.75,14.51,22.89,46.84,52.41,60.69$, $65.21,105.54,113.44,117.90,122.32,123.86,125.02$, $127.78,128.77,129.20,131.33,132.98,133.82,138.96$, $149.53,152.14,155.95,156.86,157.03,164.89,165.36$, 169.27, 170.15; IR (KBr) v: 3404, 2967, 2926, 2342, 2117 , 1734, 1702, 1594, 1547, 1483, 1448, 1367, 1307, 1231, 1161, 1133, 1060, $1009 \mathrm{~cm}^{-1}$; ESI-MS m/z: 625.4 [M$\mathrm{H}]^{-}$; HRMS calcd for $\mathrm{C}_{29} \mathrm{H}_{25} \mathrm{Cl}_{2} \mathrm{~N}_{4} \mathrm{O}_{6} \mathrm{~S}[\mathrm{M}+\mathrm{H}]^{+}$ 627.0866, found 627.0868.

2-[2-((6-(乙氧羰酯)-5-(5-氯-3-甲基-1-(4-甲氧基苯 基)-吡唑-4-基)-3-氧代-7-甲基-噻唑并 [3,2- $a$ 嘧啶2(5H)-亚基)甲基)苯氧基]乙酸(5i)：黄色固体, 产率 $64 \%$. m.p. $162 \sim 164{ }^{\circ} \mathrm{C} ;{ }^{1} \mathrm{H}$ NMR (DMSO- $d_{6}, 300 \mathrm{MHz}$ ) $\delta: 1.15$ (t, $\left.J=7.0 \mathrm{~Hz}, 3 \mathrm{H}, \mathrm{OCH}_{2} \mathrm{CH}_{3}\right), 2.27$ (s, $\left.3 \mathrm{H}, \mathrm{CH}_{3}\right)$, $2.36\left(\mathrm{~s}, 3 \mathrm{H}, \mathrm{CH}_{3}\right), 3.80\left(\mathrm{~s}, 3 \mathrm{H}, \mathrm{OCH}_{3}\right), 4.07 \sim 4.17(\mathrm{~m}, 2 \mathrm{H}$, $\left.\mathrm{OCH}_{2} \mathrm{CH}_{3}\right), 4.98\left(\mathrm{~s}, 2 \mathrm{H}, \mathrm{OCH}_{2} \mathrm{CO}\right), 6.07(\mathrm{~s}, 1 \mathrm{H}, \mathrm{CH})$, $7.02 \sim 7.18(\mathrm{~m}, 4 \mathrm{H}, \mathrm{ArH}), 7.37 \sim 7.50(\mathrm{~m}, 4 \mathrm{H}, \mathrm{ArH}), 8.05$ (s, $1 \mathrm{H}, \mathrm{ArH}$ ); ${ }^{13} \mathrm{C}$ NMR (DMSO- $\left.d_{6}, 100 \mathrm{MHz}\right) \delta: 12.73$, 14.50, 22.86, 46.94, 52.41, 55.91, 60.64, 65.35, 105.79, $113.44,114.69,116.82,120.39,122.05,122.17,122.31$, $126.72,127.75,129.20,130.86,132.95,148.40,151.89$, 155.82, 156.86, 159.46, 164.85, 165.41, 169.27, 179.16; IR (KBr) v: 3392, 3126, 2955, 2926, 2837, 2336, 1731, 1707, 1590, 1548, 1515, 1481, 1440, 1384, 1369, 1322, 1304, $1255,1230,1201,1164,1133,1080 \mathrm{~cm}^{-1}$; ESI-MS $m / z$ : $621.4[\mathrm{M}-\mathrm{H}]^{-}$; HRMS calcd for $\mathrm{C}_{30} \mathrm{H}_{28} \mathrm{ClN}_{4} \mathrm{O}_{7} \mathrm{~S}[\mathrm{M}+$ $\mathrm{H}]^{+}$623.1362, found 623.1366 .

\section{2 .5 抗肿瘤活性测试}

以 5-氟尿嘧啶(5-FU)为阳性药, 采用四甲基偶氮唑 盐(MTT)还原法测试目标化合物对人前列腺癌 PC-3 细 胞和人肝癌 HepG-2 细胞的体外抗肿瘤活性. 处于指数 生长期的细胞, 配制成浓度为 $3.5 \times 10^{4}$ 个 $/ \mathrm{mL}$ 的细胞悬 液, 96 孔细胞培养板中每孔加入 $100 \mu \mathrm{L}$ 细胞悬液(每孔 $3.5 \times 10^{3}$ 个细胞), 随后将细胞培养板置于 $37{ }^{\circ} \mathrm{C}, 5 \%$ $\mathrm{CO}_{2}$ 培养箱中培养 $24 \mathrm{~h}$. 用完全培养基稀释药物至所需 浓度, 每孔加入 $100 \mu \mathrm{L}$ 相应的含药 $(50 \mu \mathrm{mol} / \mathrm{L}$ )培养基, 同时设立阴性对照组, 阳性对照组, 96 孔细胞培养板置 于 $37{ }^{\circ} \mathrm{C}, 5 \% \mathrm{CO}_{2}$ 培养箱中培养 $72 \mathrm{~h}$. 每孔加入 $20 \mu \mathrm{L}$ MTT $(5 \mathrm{mg} / \mathrm{mL})$, 在培养箱继续培养 $4 \mathrm{~h}$ 、弃去培养基, 每孔加入 $150 \mu \mathrm{L}$ 二甲基亚砜(DMSO)溶解, 混匀 10 $\mathrm{min}$ 、酶标仪读出每孔的 OD 值 $(\lambda=490 \mathrm{~nm})$, 计算抑制 率, 计算公式如下:

抑制率 $(\%)=(1$ - 给药组吸光度值 $/$ 空白组吸光度 值) $\times 100 \%$.

$50 \mu \mathrm{mol} / \mathrm{L}$ 时抑制率大于 $50 \%$ 的样品, 重新设置浓 度进行细篎. 即将待测样品以 $0.78125,1.5625,3.125$, $6.25,12.5,25,50,100 \mu \mathrm{mol} / \mathrm{L}$ 浓度加入 96 孔板中, 培养 $72 \mathrm{~h}$, 检测. 试验结果采用 SPSS17.0 软件计算 $\mathrm{IC}_{50}$ 值.

\subsubsection{Annexin-V FITC/PI 双染法检测细胞调亡}

将指数生长期的 PC-3 细胞消化接种到六孔板中, 次日，待细胞贴壁后，根据组别设置加入相应的含有 $\mathbf{5 i}$ 培养基，同时设立阴性对照组; 药物作用 $72 \mathrm{~h}$ 后，用 $0.25 \%$ 胰酶(不含 EDTA)消化收集细胞; 用 PBS 洗涤细 胞 2 次(离心 $2000 \mathrm{r} / \mathrm{min}, 5 \mathrm{~min}$ )收集 $5 \times 10^{5}$ 细胞; 加入 $500 \mu \mathrm{L}$ 的 Binding Buffer 悬浮细胞; 加入 $5 \mu \mathrm{L}$ Annexin V-FITC 混匀后, 加入 $5 \mu \mathrm{L}$ Propidium Iodide, 混匀; 室 温、避光、反应 $5 \sim 15 \mathrm{~min}$; 最后用流式细胞仪检测 $\left(E_{\mathrm{x}}=488 \mathrm{~nm} ; E_{\mathrm{m}}=530 \mathrm{~nm}\right)$ 细胞调亡的情况. 实验重复 3 次. 


\subsubsection{PI 单染法检测细胞周期}

将指数生长期的 PC-3 细胞消化接种到六孔板中, 次日, 待细胞贴壁后, 根据组别设置加入相应的含有 $\mathbf{5 i}$ 培养基，同时设立阴性对照组; 药物作用 $72 \mathrm{~h}$ 后，用 $0.25 \%$ 肤酶(不含 EDTA)消化收集细胞; 用 PBS 洗涤细 胞 1 次(离心 $2000 \mathrm{r} / \mathrm{min}, 5 \mathrm{~min}$ )收集 $5 \times 10^{5}$ 细胞; 制备的 单细胞悬液用体积分数为 $70 \%$ 乙醇固定 $2 \mathrm{~h}, 4{ }^{\circ} \mathrm{C}$ 保存, 染色前用 PBS 洗去固定液; 加 $100 \mu \mathrm{L}$ RNase A $37{ }^{\circ} \mathrm{C}$ 水 浴 $30 \mathrm{~min}$; 再加入 $400 \mu \mathrm{L}$ PI 染色混匀, $4{ }^{\circ} \mathrm{C}$ 避光 $30 \mathrm{~min}$; 最后上机检测, 记录激发波长 $488 \mathrm{~nm}$ 处红色荧光. 实验 重复 3 次.

辅助材料(Supporting Information) 所合成化合物的 ${ }^{1} \mathrm{H}$ NMR, ${ }^{13} \mathrm{C}$ NMR, ESI-MS, HRMS 谱图. 这些材料可 以免费从本刊网站(http://sioc-journal.cn/)上下载.

\section{References}

[1] Welsch, M. E.; Snyder, S. A.; Stockwell, B. R. Curr. Opin. Chem. Biol. 2010, 14, 347.

[2] Li, L.; Liu, Q. J.; Sui, X. Y. Chin. J. Org. Chem. 2014, 34, 1669 (in Chinese). (李丽, 刘庆俭, 隋雪燕, 有机化学, 2014, 34, 1669.)

[3] Maddila, S.; Damu, G. L. V.; Oseghe, E. O.; Abafe, O. A.; Rao, C. V.; Lavanya, P. J. Korean Chem. Soc. 2012, 56, 334.

[4] Abd El-Latif, N. A.; Amr, A. E. G. E.; Ibrahiem, A. A. Monatsh. Chem. 2007, 138, 559.

[5] Holla, B. S.; Rao, B. S.; Sarojini, B. K.; Akberali, P. M. Eur. J. Med. Chem. 2004, 39, 777.

[6] Mohamed, S. F.; Flefel, E. M.; Amr, A. E. G. E.; El-Shafy, D. N. Eur. J. Med. Chem. 2010, 45, 1494.

[7] Alam, O.; Khan, S. A.; Siddiqui, N.; Ahsan, W. Med. Chem. Res. 2010, 19, 1245.

[8] Hu, J.; Wang, Y.; Wei, X. Y.; Wu, X. X.; Chen, G. Z.; Cao, G. Z.; Shen, X. Q.; Zhang, X. H.; Tang, Q. Q.; Liang, G.; Li, X. K. Eur. J. Med. Chem. 2013, 64, 292.

[9] Pan, B.; Huang, R. Z.; Zheng, L. K.; Chen, C.; Han, S. Q.; Qu, D.; Zhu, M. L.; Wei, P. Eur. J. Med. Chem. 2011, 46, 819.

[10] Ashok, M.; Holla, B. S.; Kumari, N. S. Eur. J. Med. Chem. 2007, 42,380 .

[11] Farghaly, T. A.; Gomha, S. M.; Abbas, E. M. H.; Abdalla, M. M. Arch. Pharm. Chem. Life Sci. 2012, 345, 117.

[12] Awadallah, F. M. Sci. Pharm. 2008, 76, 415.

[13] Geist, J. G.; Lauw, S.; Illarionova, V.; Illarionov, B.; Fischer, M.;
Grawert, T.; Rohdich, F.; Eisenreich, W.; Kaiser, J.; Groll, M.; Scheurer, C.; Wittlin, S.; Alonso-Gomez, J.; Schweizer, W. B.; Bacher, A.; Diederich, F. ChemMedChem 2010, 5, 1092.

[14] Zhou, B. C.; Li, X.; Li, Y.; Xu, Y. C.; Zhang, Z. X.; Zhou, M.; Zhang, X. L.; Liu, Z.; Zhou, J. H.; Cao, C. Y.; Yu, B.; Wang, R. X. ChemMedChem 2011, 6, 904.

[15] Xu, Y. C.; Zhou, M.; Li, Y.; Li, C. K.; Zhang, Z. X.; Yu, B.; Wang, R. X. ChemMedChem 2013, 8, 1345.

[16] Feng, Y.; Ding, X. D.; Chen, T.; Chen, L. L.; Liu, F.; Jia, X.; Luo, X. M.; Shen, X.; Chen, K. X.; Jiang, H. L.; Wang, H.; Liu, H.; Liu, D. X. J. Med. Chem. 2010, 53, 3465.

[17] Kolb, S.; Mondesert, O.; Goddard, M. L.; Jullien, D.; Villoutreix, B. O.; Ducommun, B.; Garbay, C.; Braud, E. ChemMedChem 2009, 4, 633 .

[18] Duval, R.; Kolb, S.; Braud, E.; Genest, D.; Garbay, C. J. Comb. Chem. 2009, 11, 947.

[19] Pathak, R. B.; Chovatia, P. T.; Parekh, H. H. Bioorg. Med. Chem. Lett. 2012, 22, 5129.

[20] Sun, N. B.; Tong, J. Y.; Wu, H. K. Chin. J. Org. Chem. 2013, 33, 101 (in Chinese). (孙娜波，童建颖，武宏科，有机化学，2013，33,101.)

[21] Liu, Y. R.; Luo, J. Z.; Duan, P. P.; Shao, J.; Zhao, B. X.; Miao, J. Y. Bioorg. Med. Chem. Lett. 2012, 22, 6882.

[22] Chavan, H. V.; Bandgar, B. P.; Adsul, L. K.; Dhakane, V. D.; Bhale, P. S.; Thakare, V. N.; Masand, V. Bioorg. Med. Chem. Lett. 2013, 23, 1315.

[23] Yang, X. H.; Zhang, P. H.; Zhou, Y. H.; Wang, J. S.; Liu, H. J. Chin. J. Chem. 2012, 30, 670.

[24] Yan, T.; Yu, S. J.; Liu, P. F.; Liu, Z.; Wang, B. L.; Xiong, L. X.; Li, Z. M. Chin. J. Chem. 2012, 30, 919.

[25] Zhang, X. Y.; Li, Y. S.; Weng, J. Q.; Tan, C. X. Chin. J. Org. Chem. 2011, 31, 1295 (in Chinese). (张向阳, 李永曙, 翁建全, 谭成侠, 有机化学, 2011, 31, 1295.)

[26] Arai, T.; Ohno, M.; Inoue, H.; Hayashi, S.; Aoki, T.; Hirokawa, H.; Meguro, H.; Koga, Y.; Oshida, K.; Kainoh, M.; Suyama, K.; Kawai, H. Bioorg. Med. Chem. Lett. 2012, 22, 5118.

[27] Li, X.; Lu, X.; Xing, M.; Yang, X. H.; Zhao, T. T.; Gong, H. B.; Zhu, H. L. Bioorg. Med. Chem. Lett. 2012, 22, 3589.

[28] Hiroyoshi, N.; Toshiaki, W.; Satoshi, Y.; Yasuhiro, M.; Katsuhiko, I.; Hiroko, S. EP 208874, 1987 [Chem. Abstr. 1987, 106, 138442].

[29] Zhou,S. G.; Ren, J. G.; Liu, M. M.; Ren, L. X.; Liu, Y. J.; Gong, P. Bioorg. Chem. 2014, 57, 30.

[30] Khilya, O. V.; Volovnenko, T. A.; Volovenko, Yu. M. Chem. Heterocycl. Com. 2006, 42, 1311.

[31] Du, H. T.; Du, H. J.; Ouyang, G. P. Chin. J. Org. Chem. 2008, 28, 356 (in Chinese). (杜海堂, 杜海军, 欧阳贵平, 有机化学, 2008, 28, 356.)

[32] Nayak, M.; Batchu, H.; Batra, S. Tetrahedron Lett. 2012, 53, 4206. 